\title{
The Effect of Pin Size on Friction Stir Welded AA5083 Plate Lap Joint.
}

\author{
Muhamad Tuah Sarhan Md Said ${ }^{1 *}$, Darulihsan Abdul Hamid ${ }^{1}$, Azman Ismail ${ }^{2}$, \\ Mohd Afendi Rojan ${ }^{3}$, Mohd Jasmin Zainuddin², Bakhtiar Ariff Baharudin², \\ and Abdul Malik Mohd $\mathrm{Ali}^{4}$ \\ ${ }^{1}$ Universiti Kuala Lumpur, Institute of Product Design and Manufacturing, Cheras, Kuala Lumpur. Malaysia. \\ ${ }^{2}$ Universiti Kuala Lumpur, Malaysian Institute of Marine Engineering Technology, Lumut, Perak. Malaysia. \\ ${ }^{3}$ School of Mechatronic Engineering, Universiti Malaysia Perlis, Pauh Putra, Perlis. Malaysia. \\ ${ }^{4}$ Universiti Kuala Lumpur, British Malaysian Institute, Gombak, Selangor. Malaysia. \\ *Email: tuahsarhan88@gmail.com.my
}

\begin{abstract}
Tool geometry plays a major role in the weld quality of friction stir welded aluminum alloys. Because of lap joint, tool geometry must be designed specifically according to the thickness of the weld specimen. Therefore, in the present work, the effect of tool geometry will be analyzed for mechanical properties of aluminum alloy 5083 weld lap joint. The result of this research shows that aluminum alloy 5083 can be joined by the friction stir welding (FSW) process, using a tapered cylindrical design pin tool with a variety of diameters (i.e $5 \mathrm{~mm}, 6 \mathrm{~mm}, 7 \mathrm{~mm}, 8 \mathrm{~mm}$ and $9 \mathrm{~mm}$ ) and a fix $20 \mathrm{~mm}$ shoulder made of H13 Steel with varying rotational speeds (910 RPM, 1280 RPM and 1700 RPM). The investigation results show the relationship between the tool geometry and the rotation speed effect on mechanical properties of the welded joint.
\end{abstract}

Keywords: Friction Stir Welding, Tool Geometry, AA5083, Plate, Lap Joint

\section{Introduction}

In FSW, a cylindrical shouldered tool with a profiled pin is rotated and plunged into the joint area between two pieces of sheet or plate material. Frictional heat between the wear resistant welding tool and the work pieces causes the latter to soften without reaching melting point $[1,2,5,15]$, allowing the tool to traverse along the weld line. In lap joints, one must distinguish between the top and bottom members, since the former is in contact with the shoulder. The end of the pin must penetrate completely through the top member, and extend some distance into the bottom member. It is not required; however, that the pin ends pass very close to the bottom of the bottom member, since, in contrast to butt joints, there is no root closure to be concerned about [1].

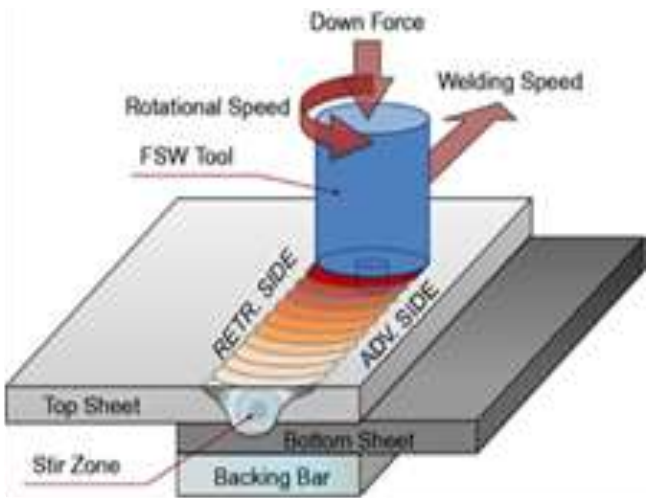

Fig. 1: FSW lap joint process

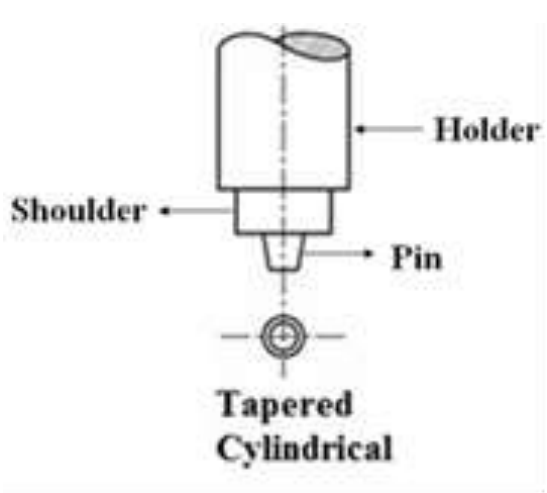

Fig. 2: Schematic figure of the tool 
The tool for FSW is basically consist of 2 parts; the pin and the shoulder. The pin creates the frictional and deformational heat, thus soften the material. On the other hand, the shoulder is designed to produce heat to the surface and subsurface region of the specimen [5]. Figure 2 shows the parts of the tool.Tool geometry has a great influence on resulting mechanical properties of the weld. It provides in-situ heating, stirs base material, and thus creates weld [1]. In Friction Stir Welding Lap Joint, the major problem occurs in the process is the depth of penetration and the size of weld region. The length of the pin and size of pin tool must be accurate in order to give maximum penetration between top and bottom base material and also produce good quality of weld joint [5]. This experiment is done in order to find the suitable pin size to join $5 \mathrm{~mm}$ A5083 Aluminium plate in lap joint position.

There are various types of tool shape in FSW process such as cylinder, tapered cylinder, triangle, rectangular, threaded or not threaded tool $[1,9]$. The shape of the tool is mainly affecting on the material flow and the weld region especially on heat affected zone and nugget zone [5,14]. The pin diameter is also play significant factor that affects the weld tensile strength and weld cross-sectional area; unsuitable diameter produce defect and low in strength [10]. One of important parameter on heat generation in FSW process is direct proportion to the size of the shoulder. Greater shoulder diameter will reduce high heat input and pressure force $[5,16]$. It is found that the shoulder diameter equal to 4 times of welded specimen is suitable to produce a sound weld [3].

The welding parameter such as rotational speed and tranverse speed are the key factor of FSW process whereby the input of welding parameter influence the heat generation and the flow of plasticised material and furthermore effecting on microstructure and mechanical properties of the specimen. A study found that these two parameters must be chosen with care to ensure a successful and efficient welding cycle. The relationship between tansverse speed and rotational speed are complex but it can be said that with the increasing of rotational speed or decreasing of transverse speed will produce a hotter weld [23]. It is also found that an increase in weld speed (tranverse speed) greatly increase the tensile strength but increase in rotational speed will resulting decrease in tensile strength $[6,14,22]$. This is because increase in rotational speed will produce more heat input thus enlarge the thermo-mechanically affected zone (TMAZ) and heat affected zone (HAZ) resulting in low tensile strength. But this theory is also depends on the shape and size of the tool, where the tool shape greatly influenced the tensile properties and joint structure in which less shape and size of tool will need high rotational speed to sufficiently produce good heat generation $[7,8,9]$.

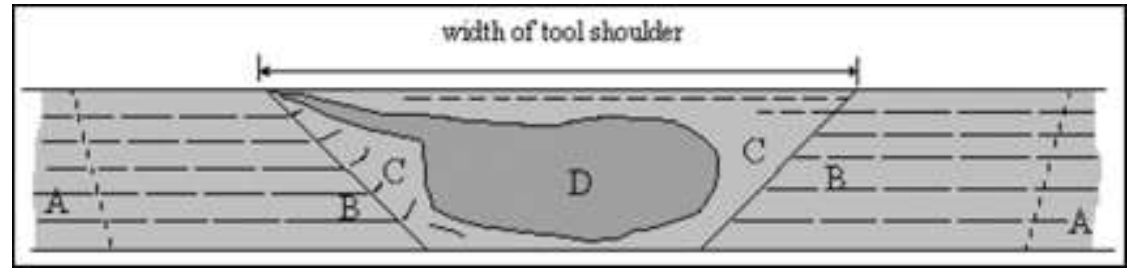

Fig. 3: Weld region

A.Unaffected material. B. Heat affected zone (HAZ). C. Thermo-mechanically affected zone (TMAZ). D. Weld nugget (part of thermo-mechanically affected zone).

The formation of weld region (see Fig. 3) is the result of the material flow from the action of the rotation of non-consumable tool. The material flow behavior is also mainly caused by the process parameters and the geometry of the rotating tool. The shape of the weld nugget and the TMAZ zone is only dependent on the shape and geometry of the welding tool and not on the welding parameter such as rotation speed or transverse speed [13].

\section{Experimental Procedure}

AISI H13 steel is used because of easy machinability, good elevated temperature strength and widely used for FSW in joining aluminium within thickness range of 0.5 to $50 \mathrm{~mm}$ [9,23]. AISI H13 steel is used in order to make 5 tool with variable of pin diameter; $5 \mathrm{~mm}, 6 \mathrm{~mm}, 7 \mathrm{~mm}, 8 \mathrm{~mm}$ and $9 \mathrm{~mm}$. The tool is designed with 
straight tapered cylindrical [7] with the pin height is $8 \mathrm{~mm}$ and fix diameter $20 \mathrm{~mm}$ [3] as shown in Figure 3. The chemical composition and mechanical properties of AISI H13 are given in Table 1 and 2 respectively. Based on tool design, experimental test were carried out according to the parameter that had been decided. The aluminium alloy 5083 plate thickness of $5 \mathrm{~mm}$ is used as specimen with specific dimension of $356 \mathrm{~mm}$ long and $102 \mathrm{~mm}$ width.

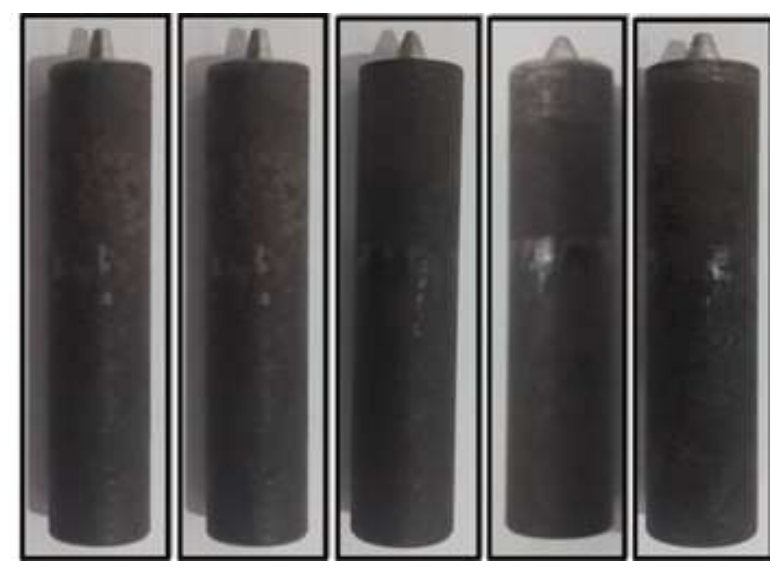

Fig. 3: Tool pin with varying pin size and profile used for this project.

TABLE 1: Material Composition H13

\begin{tabular}{|l|l|}
\hline & Content (\%) \\
\hline Chromium, Cr & $4.75-5.50$ \\
\hline Molybdenum, Mo & $1.10-1.75$ \\
\hline Silicon, $\mathrm{Si}$ & $0.8-1.2$ \\
\hline Vanadium, $\mathrm{V}$ & $0.8-1.2$ \\
\hline Carbon, $\mathrm{C}$ & $0.32-0.45$ \\
\hline Nickel, $\mathrm{Ni}$ & 0.3 \\
\hline Copper, $\mathrm{Cu}$ & 0.25 \\
\hline Manganese, $\mathrm{Mn}$ & $0.2-0.5$ \\
\hline Phosphorus, $\mathrm{P}$ & 0.03 \\
\hline Sulfur, $\mathrm{S}$ & 0.03 \\
\hline
\end{tabular}

TABLE 2: Mechanical properties H13

\begin{tabular}{|l|l|}
\hline Properties & Content $\mathbf{( \% )}$ \\
\hline $\begin{array}{l}\text { Ultimate Tensile } \\
\text { Strength }\left(@ 20^{\circ} \text { c }\right)\end{array}$ & $1200-1590 \mathrm{MPa}$ \\
\hline $\begin{array}{l}\text { Yield Strength } \\
\left(@ 20^{\circ} \mathrm{c}\right)\end{array}$ & $1000-1380 \mathrm{MPa}$ \\
\hline $\begin{array}{l}\text { Reduction of } \\
\text { Area }\left(@ 20^{\circ} \mathrm{c}\right)\end{array}$ & $50 \%$ \\
\hline $\begin{array}{l}\text { Modulus of } \\
\text { Elasticity } \\
\left(@ 20^{\circ} \mathrm{c}\right)\end{array}$ & $31200 \mathrm{ksi}$ \\
\hline Poisson's Ratio & $0.27-0.3$ \\
\hline
\end{tabular}

The experiment is carried out using universal milling machine Milko37 and with the special made fixture for Friction Stir Welding lap joint. The experimental setup is described in Figure 4 below. A cylindrical shouldered tool rotated at constant speed and plunge into the specimen for 30s. Then, it's moved at a constant transverse speed along joint line between two Aluminium plate which is butted together. The frictional heat is generated betweem wear resistant tool shoulder, pin and surface of the specimen. The heat then soften the material using the concept of mechanical mixing process and heat within the material without reaching to the material melting point [21]. 

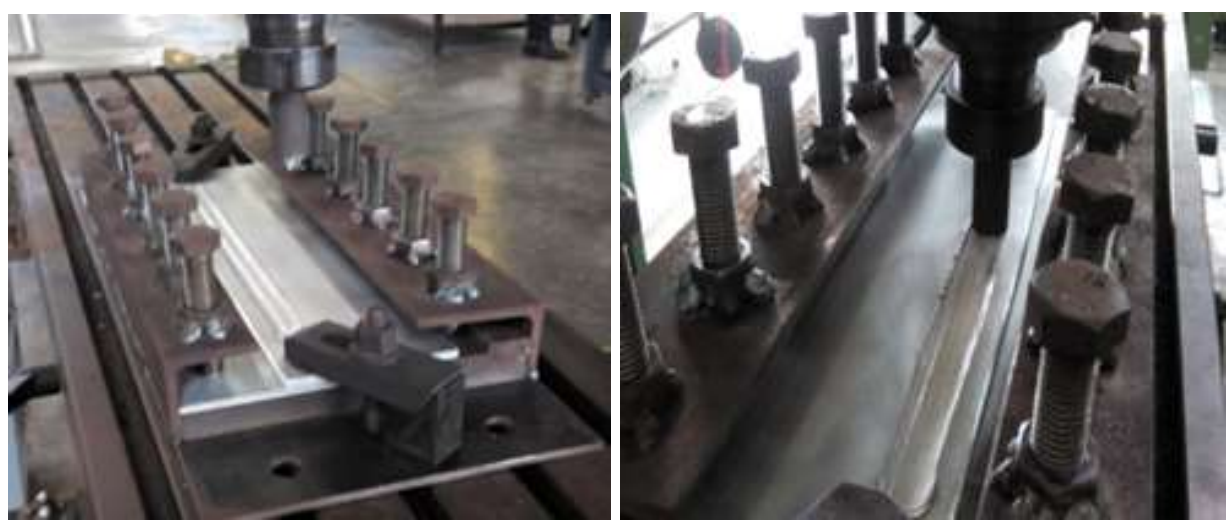

Fig 4: The experimental setup for this research

The welding parameters used for this experiment are $3^{\circ}$ of tilt angle with fix transverse speed of $16 \mathrm{~mm} / \mathrm{min}$ and variable in rotational speed; $910 \mathrm{rpm}, 1280 \mathrm{rpm}$ and $1700 \mathrm{rpm}$. After the experiment test is done, the welding sample for each parameter is taken out for visual inspection, microstructure test and tensile test. The purpose is to investigate the quality and strength of the welds and their defect. For microstructure test, the weld sample is cut into small pieces ( cross section weld region) and were polished before being inspect under microscope with 50 times zoom [17]. For the tensile test, the specimen is prepared according to AWS D17.3/D17.3M:2010 [19] and ASTM E8M-04.

\section{Result and Discussion}

From visual inspection result as shown in Figure 5, rotational speed of $910 \mathrm{rpm}$ produce smooth weld surface, compared to the $1280 \mathrm{rpm}$ and $1700 \mathrm{rpm}$. This is because the excessive heat from high rotational speed will "burn" and damaged the mechanical properties of the specimen. The heat generation in FSW is very critical and it involves mechanical mixing process thus the precise value of heat is crucial to produce a quality and high strength specimen. Always remember that the FSW process use the temperature near the melting point to join the specimen.

The size of the pin will determine the size of weld region thus determine the strength of weld itself but the size must be compatible and suitable to ensure quality of the weld is at maximum. It also found that with the increasing of rotational speed greatly affecting the size of the grain structure of the material. The weld zone becomes larger especially on the TMAZ and nugget zone resulting decrease on tensile strength of the specimen. From Tensile test result as shown in Figure 6, it shows that the pin size with rotational speed of $910 \mathrm{rpm}$ give the high tensile strength compare to the 1280 and $1700 \mathrm{rpm}$. This is because the heat produces by high rotational speed effect the microstructure of the specimen especially on weld region [2]. The heat affected zone become large and weaken the joint. The grain structure also not uniform due to excessive heat. 

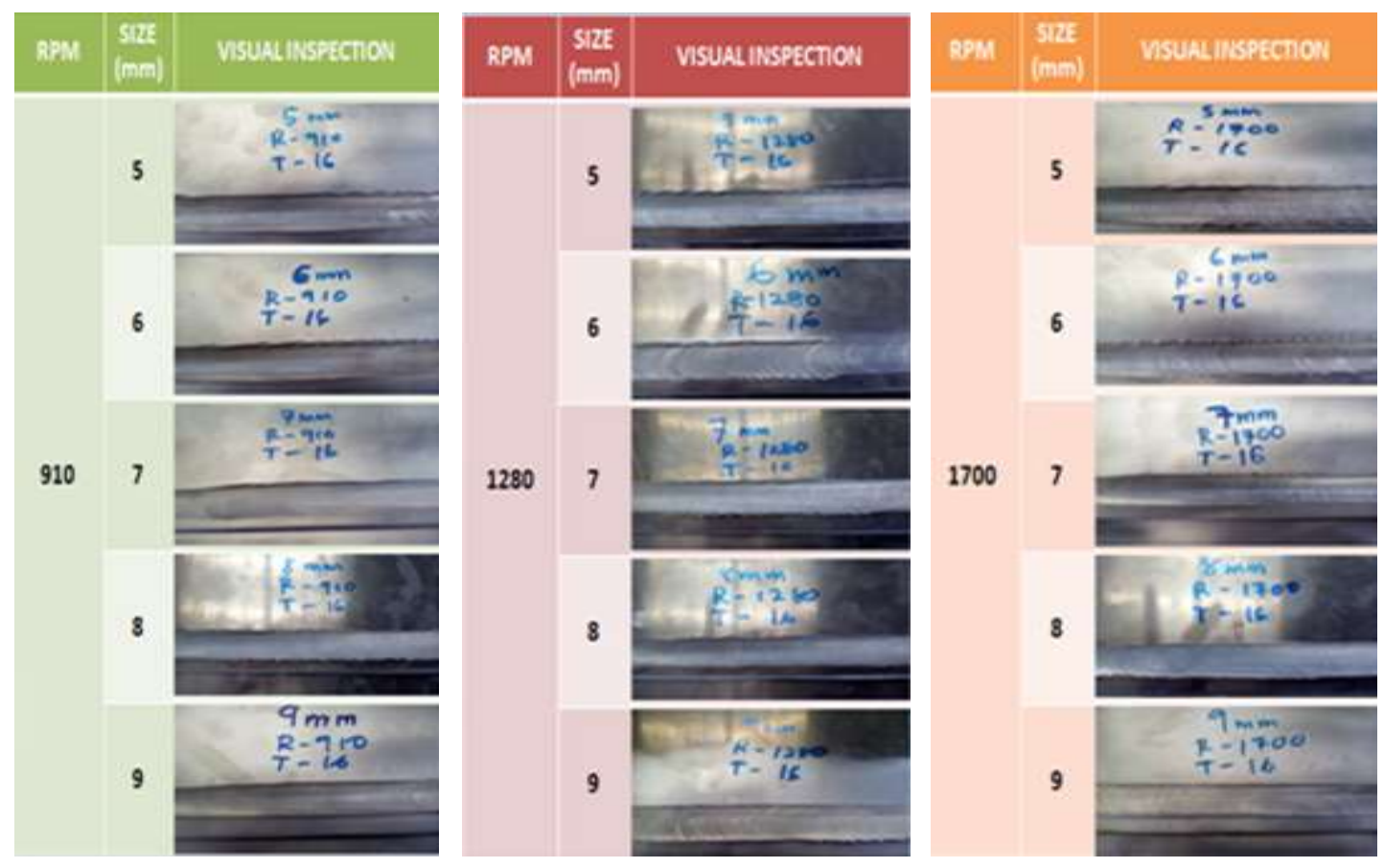

Fig. 5: External surface due to different pin profile and rotational speed

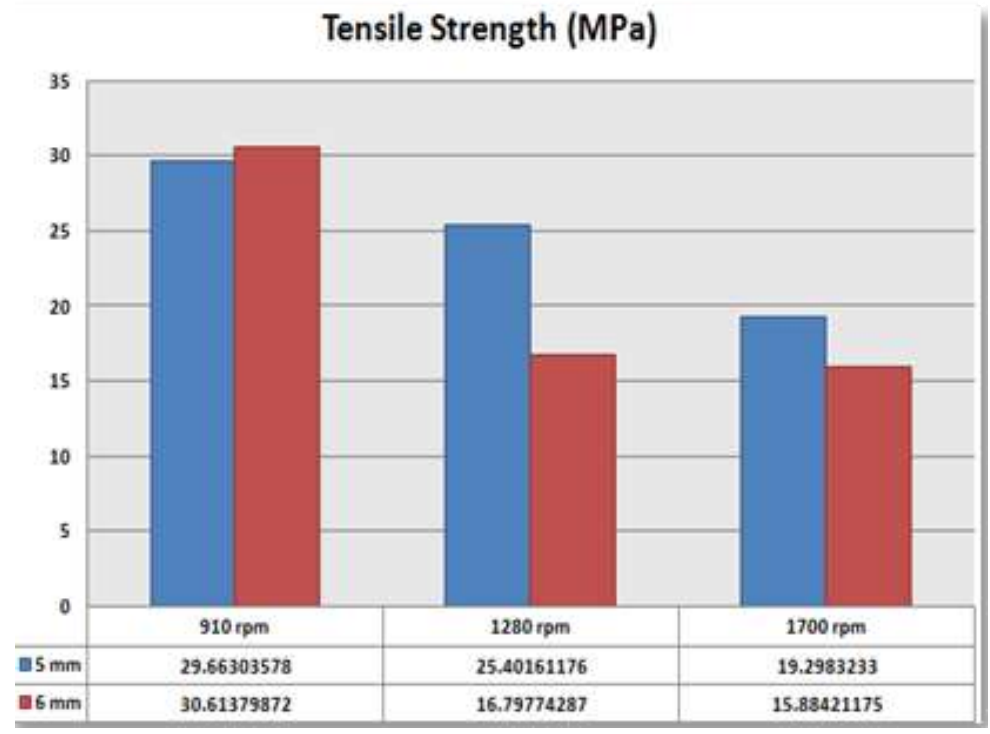

Fig. 6: Tensile test results

\section{Conclusion}

Based on the present study conducted, the optimum design of tool pin size is $6 \mathrm{~mm}$ diameter. It show better strength and quality compare to other pin size. The pin size of the tool is greatly affect the size of weld region. Meanwhile, the rotational speed affects the tensile strength and the mechanical properties of the friction stir welded specimen.

\section{Acknowledgement}

The authors thanked the Universiti Kuala Lumpur and Universiti Malaysia Perlis for facilities provided and financial assistance for this project. 


\section{References}

[1] Khaled, T. (2005). An outsider looks at friction stir welding. Fed Aviation Admin, 90712(July), 1-71. Retrieved from https://www.faa.gov/aircraft/air_cert/design_approvals/csta/publications/media/friction_stir_welding.pdf

[2] Bindu, K. D. B., \& Trivedi, P. a M. (2013). Effect of Size of Tool on Peak Temperature \& Viscosity during Friction Stir Welding of AA6061-T6 Aluminum Alloy Using HyperWorks, 2(4), 914-919.

[3] Abdelrahman, M. (2012). The effect of FSW tool geometry on AA6061-T6 weldments. Arab Journal of ..., 45(2), 407-418. Retrieved from http://www.esnsa-eg.com/researchfiles/45.pdf

[4] Muhsin J.J., Moneer H. Tolephih (2012). Effect of Friction Sitr Welding Parameters (Rotation and Tranverse) Speed on The Transient Temperature Distribution in Friction Stir Welding of AA 7020-T53, 7(4), 436-446.

[5] Meilinger, A., \& Torok, I. (2013). The Importance of Friction Stir Welding Tool. Ákos Meilinger , Imre Török. Production Processes and Systems, 6(1), 25-34.

[6] N Rajamanickam, V Balusamy. (2008). Effect of process parameter on mechanical properties of friction stir welds using design of experiments, 15, 293-299.

[7] Chouhan, D., Pal, S. K., \& Garg, S. (2013). Experimental Study on the Effect of Welding Parameters and Tool Pin Profiles on Mechanical Properties of the FSW Joints, 3(5), 1972-1978.

[8] Patil, H, \& Soman, S. . (2010). Experimental study on the effect of welding speed and tool pin profiles on AA6082-O aluminium friction stir welded butt joints. International Journal of Engineering, Science and Technology, 2(5), 268275. doi:10.4314/ijest.v2i5.60163.

http://dx.doi.org/10.4314/ijest.v2i5.60163

[9] Zhang, Y. N., Cao, X., Larose, S., \& Wanjara, P. (2012). Review of tools for friction stir welding and processing. Canadian Metallurgical Quarterly, 51(3), 250-261. doi:10.1179/1879139512Y.0000000015 http://dx.doi.org/10.1179/1879139512Y.0000000015

[10] Venkateswarlu, D., \& Mandal, N. (2013). Tool Design Effects for FSW of AA7039. Welding Journal. Retrieved from http://files.aws.org/wj/supplement/WJ_2013_02_s41.pdf

[11] Hirano, S. (2008). Friction Stir Welding. Journal of the Japan Welding Society, 77, 446-448. doi:10.2207/jjws.77.446 http://dx.doi.org/10.2207/jjws.77.446

[12] Rohilla, P., \& Kumar, N. (2013). Experimental investigation of Tool Geometry on Mechanical Properties of Friction Stir Welding of. International Journal of Innovative Technology and Exploring Engineering, 3(3), 56-61.

[13] Chionopoulos, S. K., Sarafoglou, C. H. I., Pantelis, D. I., \& Papazoglou, V. J. (2008). Effect of Tool Pin and Welding Parameters on Friction Stir Welded ( Fsw ) Marine Aluminium Alloys, (October), 1-3.

[14] Sidhu, M. S., \& Chatha, S. S. (2012). Friction Stir Welding - Process and its Variables : A Review, 2(12).

[15] Avula, D., Kumar, R., \& Singh, R. (2011). Effect of Friction Stir Welding on Microstructural and Mechanical Properties of Copper Alloy, 183-191.

[16] Al-araji, N. M., Kadum, K. M., \& Al-dayni, A. a. (2011). Effect of friction stir welding pressure on the microstructure and mechanical properties of weld joints, 2(12), 1-5.

[17] Leitão, C., Leal, R. M., Rodrigues, D. M., Vilaça, P., \& Loureiro, a. (2008). Material flow in Friction Stir Welding. Microscopy and Microanalysis, 14(supp 3), 87. doi:10.1017/S1431927608089472

http://dx.doi.org/10.1017/S1431927608089472

[18] DebRoy, T., \& Bhadeshia, H. K. D. H. (2010). Friction stir welding of dissimilar alloys - a perspective. Science and Technology of Welding \& Joining, 15(4), 266-270. doi:10.1179/174329310X12726496072400 http://dx.doi.org/10.1179/174329310X12726496072400

[19] AWS-D17.3/D17.3M:200X. (2010). Specification for Friction Stir Welding of Aluminum Alloys for Aerospace Applications. American Welding Society, 1-60.

[20] Azman Ismail, Mokhtar Awang, Friction stir welding on aluminum alloy 6063 pipe, Proceedings of the 7th Asia Pacific IIW International Congress, Singapore, 2013, pp.78-81. 